\title{
Updated Heliostorm Warning Mission: Enhancements Based on New Technology
}

\author{
Roy M. Young, \\ NASA George C. Marshall Space Flight Center, Huntsville, AL 35812
}

\begin{abstract}
The Heliostorm (also referred to as Geostorm) mission has been regarded as the best choice for the first application of solar sail technology. The objective of Heliostorm is to obtain data from an orbit station slightly displaced from the ecliptic at or nearer to the Sun than $0.98 \mathrm{AU}$, which places it twice as close to the sun as Earth's natural $\mathrm{L1}$ point at $0.993 \mathrm{AU}$. The maintenance of such an orbit location would require prohibitive amounts of propellants using chemical or electric propulsion systems; however, a solar sailcraft is ideally suited for this purpose because it relies solely on the propulsive force from photons for orbit maintenance. Heliostorm has been the subject of several mission studies over the past decade, with the most complete study conducted in 1999 in conjunction with a proposed New Millennium Program (NMP) Space Technology 5 (ST-5) flight opportunity. Recently, over a two and one-half year period dating from 2003 through 2005 , NASA's In-Space Propulsion Technology Program (ISTP) matured solar sail technology from laboratory components to full systems, demonstrated in as relevant a space environment as could feasibly be simulated on the ground. Work under this program has yielded promising results for enhanced Heliostorm mission performance. This enhanced performance is achievable principally through reductions in the sail areal density. These reductions are realized through the use of lower linear mass density booms, a thinner sail membrane, and increased sail area. Advancements in sailcraft vehicle system design also offer potential mass reductions and hence improved performance. This paper will present the preliminary results of an updated Heliostorm mission design study including the enhancements incorporated during the design, development, analysis and testing of the system ground demonstrator.
\end{abstract}

\section{INTRODUCTION}

Solar sail propulsion uses sunlight to propel vehicles through space by reflecting solar photons from a large, mirror-like sail made of a lightweight, reflective material. Because the Sun supplies the necessary propulsive energy, solar sails also require no onboard propellant, thus reducing payload mass. The NASA Science Mission Directorate (SMD) Earth-Sun Systems Division's Heliophysics Roadmap ${ }^{1}$ has identified a number of missions that can be enhanced by solar sails. For example, the continuous photonic pressure provides propellantless thrust to hover indefinitely at points in space (e.g. Heliostorm/L1) or conduct orbital maneuver plane changes (e.g. Solar Polar Imager) much more efficiently than conventional chemical propulsion. Eventually, a solar sail might propel a space vehicle to tremendous speedstheoretically much faster than any present-day propulsion system - to reach interstellar space and explore the heliopause (e.g. Inter Stellar Probe).

\section{Heliostorm Mission Concept}

The space between the sun and the planets is filled with particles and fields that are constantly changing. Driven by solar events and modulated by planetary magnetic fields, this changing "space weather" affects humans and our technological systems. Solar events such as flares and coronal mass ejections (CME) accelerate atomic particles to energies as high as $1 \mathrm{geV}$, enough to penetrate any practical

Systems Engineer, Instrument \& Payload Systems Department/EI61, AIAA Member 
shielding that astronauts or spacecraft could carry. CMEs throw billions of tons of matter and entangled magnetic fields into interplanetary space at speeds up to 10 million $\mathrm{km} / \mathrm{h}$. When a CME hits the Earth, it interacts with the magnetosphere and induces ground currents that can overwhelm electric power distribution systems, causing blackouts and induce currents in exposed oil pipelines, leading to higher maintenance costs. Space storms also heat and inflate the atmosphere, thus altering spacecraft orbits; change the properties of the ionosphere disrupting communication links and causing errors in GPS navigation; interrupt spacecraft operations by causing latch-ups in electronics; pose life-threatening radiation hazards to astronauts working outside the magnetosphere; and boost radiation in aircraft flying over the poles. Better engineering can mitigate many of these effects, but accurate forecasts of impending storms is still required to avoid costly downtime and life-threatening radiation hazards.

The Heliostorm mission will measure the solar wind and heliosphere state "upstream" of the Earth and Moon. Through the use of breakthrough solar sail technology, it would fly $50 \%$ further from the Earth (farther upstream) than the current Advance Composition Explorer (ACE) measurement at the Earth-Sun L1. A set of in-situ measurements then would provide $50 \%$ greater warning time (compared to ACE) of CMEs and shock-accelerated energetic particles. In conjunction with other assets outside the Earth's magnetosphere, the mission would determine the structure of the solar wind on spatial and temporal scales that are relevant for driving magnetospheric processes. Heliostorm will support the Vision for Space Exploration by providing an input that is absolutely vital to the prediction of space weather in cislunar space. Astronauts on the lunar surface will benefit greatly as the enhanced warning time will permit reaction to actual upstream conditions measured by Heliostorm. The solar wind input to the Earth is required by all models of the Earth's magnetosphere, and would be provided by Heliostorm or a conventional $\mathrm{L} 1$ monitor. Heliostorm (or a conventional $\mathrm{L} 1$ monitor) must be flown in time to replace the current ACE/Wind configuration. This suggests a launch in the 2016-2020 time frame.

The Heliophysics Roadmap identified Heliostorm as the most likely first mission that could utilize a solar sail. The concept for the Heliostorm mission originated in the summer of 1996 after NOAA asked the Jet Propulsion Laboratory (JPL) whether an improvement in the warning time available from a satellite positioned at $\mathrm{L} 1$ could be achieved through the application of emerging new technologies in solar sails, inflatable structures, and microspacecraft. NOAA's principal motivation was to find an inexpensive, reliable way to continue the delivery of storm warning data to its commercial and DoD customers after the expected end-of-life of the Advanced Composition Explorer (ACE) spacecraft in 2000-2002.

The results of the ensuing 1996 JPL study ${ }^{2,3}$ showed a viable mission/satellite system concept to provide the desired improvement in storm waning time. The satellite could utilize small satellite technology merged with a space-inflatable solar sail to take advantage of solar photon pressure to permit the satellite to maintain an unnatural station near the Earth-Sun line at $-0.98 \mathrm{AU}$, well inside the $\mathrm{L} 1$ point at $-0.993 \mathrm{AU}$. So positioned, the satellite could provide a factor of 3 increase in warning time over the 30 minutes to 1 hour available at L1. The satellite could be based on conventional technology, and the sail could utilize a space-inflated, rigidizable structure. Subsequent updates to the work ${ }^{4,5}$, carried the original 1996 work several important steps further, adding detail to the design of both the sailcraft bus and sail and refining the sailcraft performance estimates to a more achievable factor of 2 increase in warning time while at the same time validating the original Geostorm system concept and its estimated costs. This latter work was sponsored by NASA's New Millennium Program (NMP) in the context of a competition for NASA's FY '00 Space Technology 5 (ST-5) technology flight validation opportunity, leading to a formal project proposal presented to NASA Headquarters by JPL in the summer of 1999 for a project known as the SubL1 Sail Project. That mission, as then envisioned, offered a logical follow-on inflatable structure flight demonstration to the NASA Inflatable Antenna Experiment (IAE) completed in May 1996, taking that demonstration several critical steps further in demonstrating both the deployment of a substantially larger structure than demonstrated on IAE and in-flight structural rigidization. At the same time, the mission would have served an important national need in providing solar storm warning alerts to commercial, DoD, and NASA customers.

Unfortunately, the ST-5 Solar Sail proposal was not selected, however key concepts from the ST-5 proposal were incorporated by L'Garde into a winning proposal to the In-Space Propulsion Technology (ISPT) Program's Research Opportunities in Space Science (ROSS) NASA Research Announcements (NRA) announcement in 2002. 


\section{20 meter Ground System Demonstrators}

The ISPT goal is the advancement of key transportation technologies that will enable or enhance future robotic science and deep space exploration missions. At the program's inception, a set of technology investment priorities were established using a NASA-wide prioritization process and, for the most part, these priorities have changed little - thus allowing a consistent framework in which to fund and manage technology development. Technologies in the portfolio include aerocapture, advanced chemical propulsion, solar electric propulsion, and solar sail propulsion (SSP).

The first of two SSP research elements in the ISTP Cycle 1 was called the Ground System Demonstration (GSD), which developed a prototype solar sail system for ground testing that would be used to validate design concepts for: sail manufacturing, packaging, launch to space and deployment; attitude control subsystem function; and to characterize the structural mechanics and dynamics of the deployed sail in a simulated space environment. The solicitation called for a square sail configuration consisting of a reflective sail membrane, a deployable sail support structure, an attitude control subsystem, and all hardware needed to stow the sail for launch. In addition this system was required to meet the characteristics given in Table 1, columins 1 and 2. A sub-L1 solar monitoring mission concept was also provided as a reference mission for guidance in design and scalability issues, and is summarized in Table 2 .

SSP awarded ground demonstration contracts to two companies that had proposed two distinct technologies in order to achieve the project objectives. ABLE Engineering Company's (now ATK Space Systems) proposed work based on their prior NMP ST-7 proposal, incorporating a rigid coilable boom, an articulating boom attitude control system (ACS) subsystem and partner SRS, Inc.'s CP1 sail membrane. L'Garde, Inc. proposed work based on the experience they gained on their NMP ST 5 proposal and as the sail provider for a commercial venture, Team Encounter, incorporating an inflatable and sub-Tg rigidizable boom, a control vane based ACS and commercial mylar for the sail membrane. The parallel testing and development of these two system level demonstrations using varied technologies in the three major subsystems removed the risk to this technology development if one provider encountered an unrecoverable failure. The system level ground demonstration work was divided into three phases. A six month concept refinement phase was completed in May, 2003. During this phase, the two teams provided analysis of their system's performance when scaled to the Design Reference Mission and a preliminary test plan for the following two twelve-month phases. The twelve-month hardware development phase began in June, 2003. In this phase both teams built and tested components and subsystems, with ATK concentrating on a single 10-meter quadrant and L'Garde developing a 10-meter square sail. The most comprehensive of these tests occurred in the middle of 2004 when the respective teams deployed their integrated subsystem in the LaRC 14-meter vacuum facility (ATK) and the 30-meter vacuum chamber at Glenn Research Center's Plum Brook Space Power Facility (L'Garde). Following a successful second phase the teams culminated their work in a twelve-month system verification phase. In this phase both teams built and tested fully integrated 20-meter sail systems that included a launch packaging container, and operational ACS subsystems. In the middle of 2005, the respective teams tested their system in the NASA Glenn Research Center's Space Power Facility at Plum Brook under a high vacuum and appropriate thermal environment, as well as subjecting their systems to launch vibration and ascent vent tests. Figures 1 and 2 show the 20 -meter deployed systems at Plum Brook, while columns 3 and 4 of Table 1 summarize the final program metrics

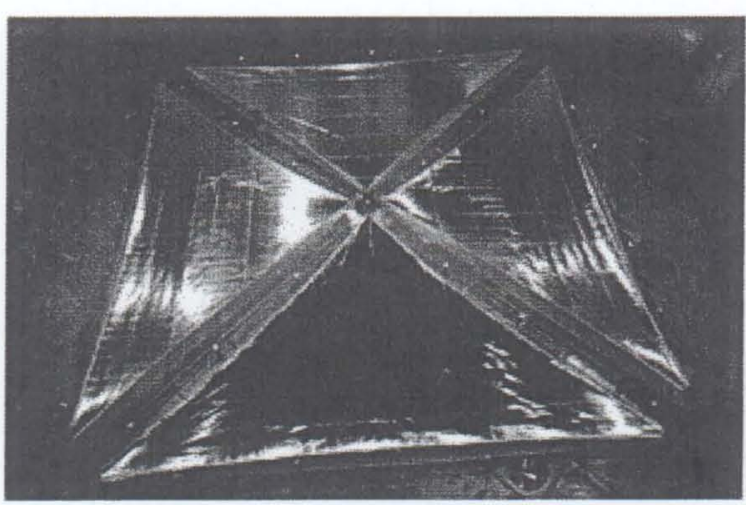

Figure 1: ATK System Deployed

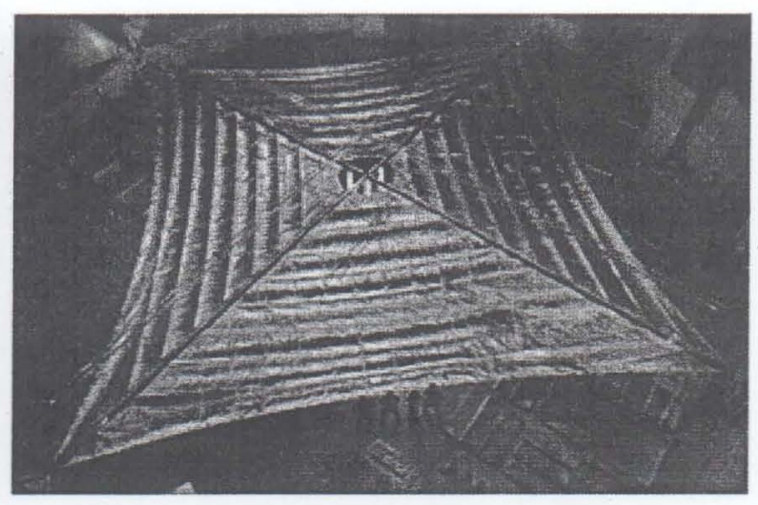

Figure 2: L'Garde System Deployed

American Institute of Aeronautics and Astronautics 
achieved by L'Garde and ATK. Since these sails represent the largest ground systems that will be deployed and tested in the world's largest vacuum chamber, a significant effort was made to collect static and dynamic data on the sails and booms with approximately $400 \mathrm{~Gb}$ of data collected, primarily raw photogrammetry data. Technical descriptions of work being performed by $\mathrm{AEC}^{6,7,8,9}$ and L'Garde ${ }^{10,11,12}$ on the 20-meter GSD can be found in the respective team's papers.

Table 1.: Ground System Demonstration Metrics

\begin{tabular}{|c|c|c|c|}
\hline METRIC & RFP & ATK & - L'GARDE \\
\hline Dimensions: & $\begin{array}{ll}20 \text { meters } \times 20 \\
\text { meters } & \text { or } \\
\text { greater } & \end{array}$ & $\begin{array}{l}\text { - } 20 \text {-m system with flight like } \\
\text { central structure } \\
\text { - } 4 \text { sails scaled from } 80 \mathrm{~m} \\
\text { - Truncated } 80 \mathrm{~m} \text { masts } \\
\text { - Central structure scaled from } \\
40-\mathrm{m}\end{array}$ & $\begin{array}{l}\text { - } 19.5 \mathrm{~m} \text { due to Plumbrook } \\
\text { - } 1 \text { subscale TVCAD vane } \\
\text { - Non-flight central structure } \\
\text { scaled for } 100 \mathrm{~m} \text { system } \\
\text { - Sails and mast truncated } \\
100 \mathrm{~m} \text { system }\end{array}$ \\
\hline $\begin{array}{l}\text { Sail Subsystem } \\
\text { Areal Density }\end{array}$ & $\begin{array}{l}<\quad 20 \quad \mathrm{~g} / \mathrm{m}^{2} \\
\text { (scalability to } \\
12 \mathrm{~g} / \mathrm{m}^{2} \text { for } \\
104 \mathrm{~m} 2 \text { ) }\end{array}$ & $\begin{array}{l}\text { - } 112 \mathrm{~g} / \mathrm{m}^{2}-\text { includes } \\
\text { spacecraft bus structure, } \\
\text { ACS, power, instrument } \\
\text { boom } \\
\text { - scaled to } 11.3 \mathrm{~g} / \mathrm{m} 2 \text { for } 100 \mathrm{~m} \\
\text { design and no payload }\end{array}$ & $\begin{array}{l}\text { - } 30 \mathrm{~g} / \mathrm{m}^{2} \text { - includes ACS ( } \\
\text { vanes calculated), centra } \\
\text { structure dropped } \\
\text { - scaled to } 14.1 \mathrm{~g} / \mathrm{m}^{2} \text { with } 50 \mathrm{~kg} \\
\text { payload and } 41.4 \mathrm{~kg} \text { bus }\end{array}$ \\
\hline $\begin{array}{l}\text { Stowed } \\
\text { Volume }\end{array}$ & $\begin{array}{l}<\quad 0.5 \mathrm{~m}^{3} \\
\text { (scalability to } \\
1.5 \mathrm{~m}^{3} \text { for } 104 \\
\mathrm{~m}^{2} \text { ) }\end{array}$ & $\begin{array}{l}0.9 \mathrm{~m}^{3} \text { scaled to } 1.5 \mathrm{~m}^{3} \text { for } \\
100 \mathrm{~m} \text { design }\end{array}$ & $\begin{array}{l}2.14 \mathrm{~m}^{3} \text { scaled to } 1.04 \mathrm{~m}^{3} \text { fo } \\
100 \mathrm{~m} \text { design }\end{array}$ \\
\hline $\begin{array}{l}\text { Thrust Vector } \\
\text { Turning Rate } \\
\text { about roll axis: }\end{array}$ & $>1.5^{\circ} / \mathrm{hr}$ & - $>35^{\circ}$ maneuver in $2 \mathrm{hrs}$ & - $63^{\circ} /$ hour $(.0$ \\
\hline $\begin{array}{l}\text { Effective Sail } \\
\text { Reflectance }\end{array}$ & $>0.75$ & - $92 \%$ over solar spectrum & - 85.9 \\
\hline $\begin{array}{l}\text { Anti-sunward } \\
\text { Emissivity }\end{array}$ & $>0.30$ & 3 micron film & - 0.40 \\
\hline $\begin{array}{l}\text { Membrane } \\
\text { Characteristics }\end{array}$ & $\begin{array}{l}\text { space-durable, } \\
\text { tear-resistant, } \\
\text { designed for } 1 \\
\text { year in the } \\
\text { near-GEO } \\
\text { environment }\end{array}$ & $\begin{array}{l}-2 \text { micron CP1 with } 1000 \mathrm{~A} \\
\text { of aluminum on front, bare } \\
\text { CP1 on back of sail. All } \\
\text { materials have space flight } \\
\text { heritage. }\end{array}$ & $\begin{array}{l}\text { - } 2 \text { micron Mylar with } 1000 \mathrm{~A} \\
\text { of aluminum on front and } \\
200 \mathrm{~A} \text { blackened chromium } \\
\text { on back }\end{array}$ \\
\hline $\begin{array}{l}\text { System } \\
\text { Flatness }\end{array}$ & $\begin{array}{l}\text { Effective for } \\
\text { Propulsion }\end{array}$ & $\begin{array}{l}\text { - 3-point quadrant support } \\
\text { with shear compliant } \\
\text { border to insure a flat sail, } \\
\text { with a proper stress level to } \\
\text { obtain local flatness } \\
\end{array}$ & - Stripped net loss $\sim 2 \%$ \\
\hline$\overline{\mathbf{A C S}}$ & $\begin{array}{l}\text { 3-axis, } \\
\text { minimize } \\
\text { propellant } \\
\text { usage }\end{array}$ & $\begin{array}{l}\text { - Sliding trim control mass on } \\
\text { truss and tip bars to } \\
\text { pinwheel quadrants for roll. } \\
\text { Micro PPT backup }\end{array}$ & $\begin{array}{l}\text { Totally propellantless using } \\
\text { four tip vanes }\end{array}$ \\
\hline
\end{tabular}


Table 2. Design Reference Mission

\begin{tabular}{|c|c|c|c|c|c|c|c|c|}
\hline $\begin{array}{c}\text { Launch } \\
\text { Mass (kg) }\end{array}$ & $\begin{array}{c}\text { Payload } \\
\text { Mass (kg) }\end{array}$ & $\begin{array}{c}\text { Payload } \\
\text { Power (W) }\end{array}$ & $\begin{array}{c}\text { Total } \\
\text { Power } \\
(\mathbf{W})\end{array}$ & $\begin{array}{c}\text { TM } \\
\text { Dish } \\
(\mathbf{m})\end{array}$ & $\begin{array}{c}\text { TM } \\
\text { Band }\end{array}$ & $\begin{array}{c}\text { TM } \\
\text { Rate } \\
(\mathbf{K b} / \mathbf{s})\end{array}$ & $\begin{array}{c}\text { S/C } \\
\text { Dia (m) }\end{array}$ & $\begin{array}{c}\text { Launch } \\
\text { Vehicle }\end{array}$ \\
\hline 250 & 50 & 100 & 750 & 1.5 & $\mathrm{X}$ & 100 & $<2.3$ & $\begin{array}{c}\text { Delta } \\
2425-9.5\end{array}$ \\
\hline
\end{tabular}

\section{MISSION PERFORMANCE COMPARISON: OLD 1999 NMP ST-5 SUB-L1 SAIL}

\section{A. Sailcraft Performance}

The 1999 NMP ST-5 Sub-L1 Sail Project proposal Geostorm sailcraft could enable a factor of 2 increase in warning time compared to a conventional satellite stationed at the LI point ${ }^{5}$. This increase in warning time, which required artificially displacing the $\mathrm{L} 1$ equilibrium point from $0.993 \mathrm{AU}$ to $0.984 \mathrm{AU}$, was achieved with a sail concept developed by L'Garde, Inc. of Tustin, CA which utilized an inflatable UV-rigidized boom and a sailcraft and sailcraft bus concept developed by Ball Aerospace Corp., Boulder, $\mathrm{CO}$, in conjunction with JPL. Figure 3 shows, respectively, the overall sailcraft configuration, the sailcraft bus, and the sailcraft bus hardware layout. The paragraphs that follow describe the design's key features, and Reference 5 documents the design in detail. The overall sailcraft system could achieve beginning-oflife and end-of-life sailcraft loadings of 42.1 and $36.3 \mathrm{grams} / \mathrm{m}^{2}$, respectively, sufficient to achieve an operational station location between 0.984 and 0.983 AU.

\section{B. Sail Design}

The 1999 NMP ST-5 Geostorm sail design utilized UV-rigidized, Kevlar, 4.5-mil-wall-thickness, inflatable struts, a 0.33-mil (8-micron) thick Kapton sail membrane, and a jettisonable stowage canister and inflation system. The total launch mass of the sail, or Sail Propulsion Subsystem (SPS), was $78.7 \mathrm{~kg}$, including $7 \mathrm{~kg}$ of jettisonable elements, making the flight or operational mass of the SPS $71.7 \mathrm{~kg}$. The jettisonable element mass included $5 \mathrm{~kg}$ for the stowage canister and $2 \mathrm{~kg}$ for the inflation system. The boom linear mass density for the tapered $8 \mathrm{~cm}$-diameter boom at the base and $2.5-\mathrm{cm}$ diameter boom at the tip was $41.1 \mathrm{~g} / \mathrm{m}$.

\section{Sailcraft Design}

The sailcraft is comprised of the sailcraft bus, solar sail, sail stowage canister, and a three-instrument payload. The sailcraft employs spin stabilization for attitude control, utilizes conventional monopropellant hydrazine propulsion to control sailcraft orientation and perform trajectory correction maneuvers (TCM), and has a jettisonable sail used if the sail fails to deploy properly. Spin stabilization was selected for attitude control after studies of other options such as 1) conventional 3-axis control showed that option to require a prohibitively large amount of propellant to counter the perturbing effects of solar torque, the dominant external perturbation to the sailcraft, and 2) a moving-mass 3-axis concept, which would enable active mulling of the sailcraft center-of-mass/center-of-pressure offset through control of the location of the sailcraft center-of-mass, showed that option to be more complex and costly. ${ }^{13}$. The selection of conventional propulsion for sailcraft attitude orientation control was a natural given it was already required to perform TCMs during the ballistic transfer to $L 1$ and that its selection would minimize the risk to sailcraft development that would be imposed by trying to use other alternatives to orientation control like vanes. Also, the use of conventional propulsion offered, together with the capability for sail jettison, the advantage of permitting the sailcraft to operate - and hence perform a conventional L1 Geostorm mission without the sail were the sail not to deploy properly and have to be jettisoned. In addition to the reason just noted, this capability was also considered critical to lay the foundation for other sail missions expected to employ the sail as a propulsion stage to be jettisoned upon arrival at a target of interest to permit, for example, high-precision pointing that could be compromised by having a large, difficult-to-maneuver, permanently-attached sail in tow. 

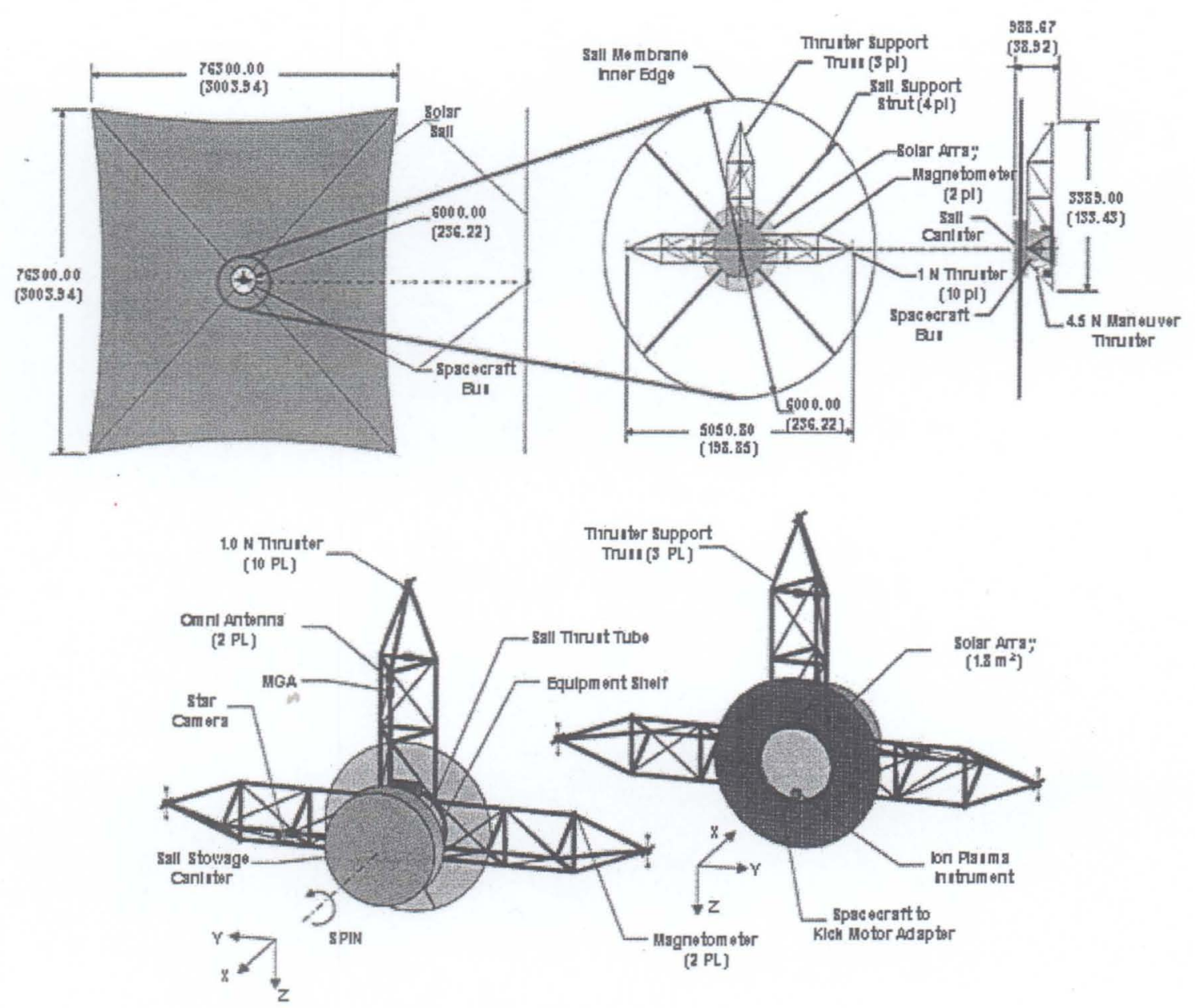

Figure 3: ST-5 Sailcraft Design

\section{Sail Deployment}

Deployment proceeds in positive and negative directions along one axis and then along the orthogonal axis. A blowdown inflation system with a regulated pressure is used for simplicity and lightweight. A latching valve for each axis allows axis sequencing as well as deployment halt in case of an anomaly. Contacts at each ring ( 1-m intervals) on each boom allow monitoring of all boom/sail positions during deployment. The inflation system is jettisoned after deployment and rigidization to lower sailcraft areal density. The operator will be able to bypass regulated pressure in the unlikely event of a tube hang up.

The sail is attached to the booms via rings at $\sim 1$-meter intervals. Therefore, the boom deployment control also controls sail deployment; no mechanisms are added. The sail is pulled out from points all along its length rather than just from the tip. If the first axis fails to deploy completely, the second axis of the sail can still be pulled fully out. Also, since the inboard section of sail is deployed first, sail tensioning can still be accomplished in the event of incomplete boom deployment.

\section{E. Mission Design}

This phase of mission starts with a transfer from a $200-\mathrm{km}$ Earth parking orbit to a Halo orbit similar to the one used for GENESIS4. The assumed departure from LEO is October 10, 2008 and the Halo orbit injection occurs on January 25, 2009. The total transfer time is 107.6 days. After arriving at L1-halo and confirming that the sail deployment is successful, solar sailing will be initiated to go to Sub-L1 point with the departure time arbitrarily set to 60 days after the L1-Halo orbit injection. As shown in Figure 4, the characteristic acceleration, required for a $0.98-\mathrm{AU}$ Sub-L1 station is $0.31 \mathrm{~mm} / \mathrm{s}^{2}$. 


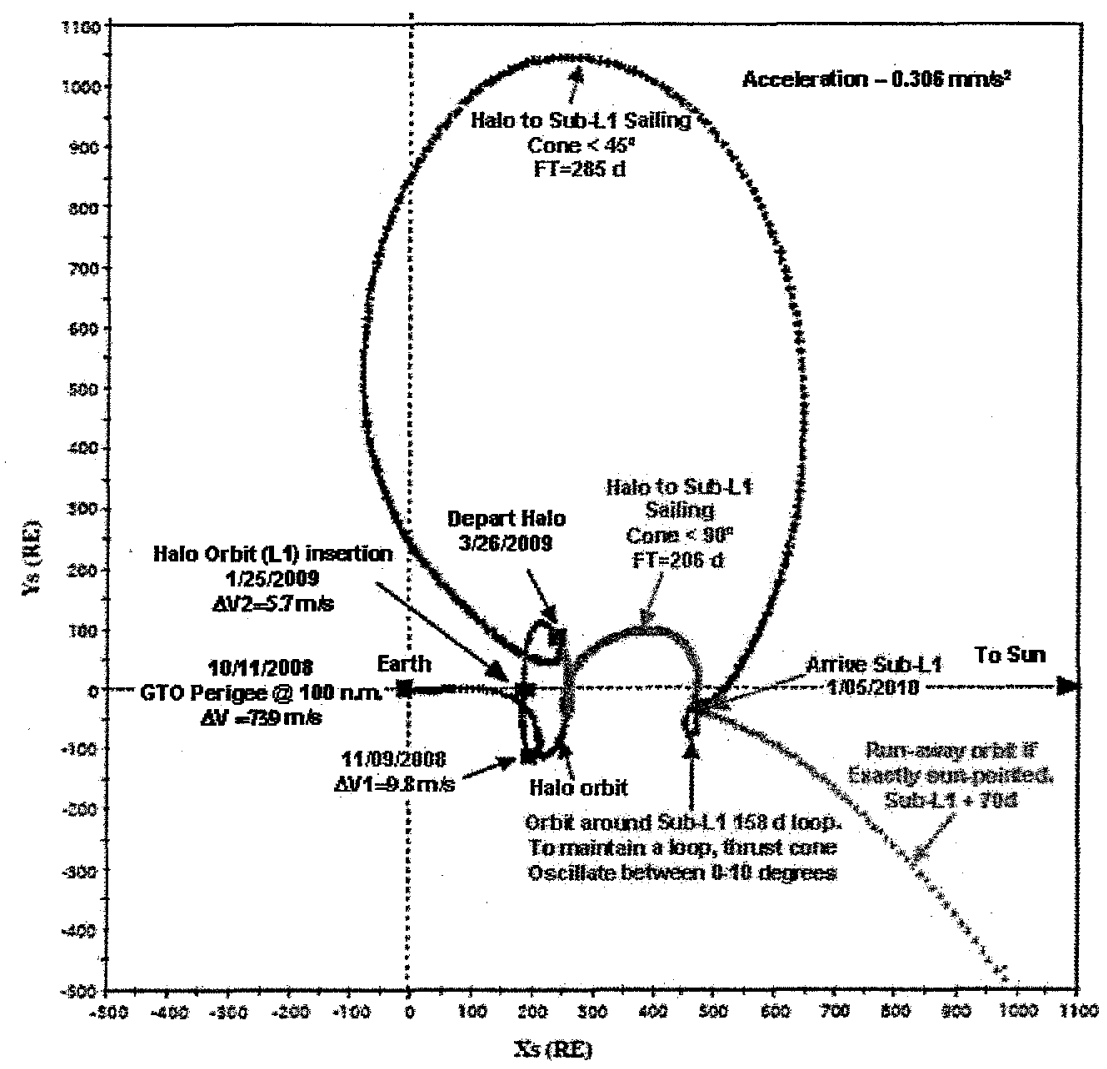

Figure 4: ST-5 Mission Design

The design of the Halo to Sub-L1 orbit transfer is based on 1) a perfect sail model and 2) the minimumtime steering law. Current sail technology predicts uncertain performance when the sail is tilted more than 45 degrees away from Sun. So, two types of trajectories were generated, namely without and with the $45^{\circ}$ cone angle constraint. The resulting orbits are shown in Figure 4, which contains: 1) the ballistic orbit from LEO to L1-Halo orbit, 2) the Halo Orbit, 3) the orbit from Halo to Sub-L1 without cone angle constraint, 4) the orbit from Halo to Sub-L1 with 45 degree cone angle constraint, 5) the runaway path from Sub-L1 if cone angle were fixed at 0 degree, and 6) a 180-day closed loop about Sub-L1 representing a mode of station keeping. Note that the Sub-L1 point as shown is biased off the Earth-Sun line (i.e. Ys= $-40 \mathrm{RE}$ ) in order to satisfy communication's requirement to avoid pointing directly at the Sun.

\section{Updated Geostorm Sailcraft Performance and Design}

Missions that might benefit from the use of very large structures in space place a high value on massefficient structures and, for sail missions, on space-suitable thin-film membranes. The reason for this is obvious: for missions requiring large space structures most of the mass is in the structure and therefore most of the potential mass savings lies in the structure. Also important to note, specifically for sail missions, is the desire to reduce not only launch mass but also to eliminate mass post launch. Sail missions can continue to benefit from the staging principle after completion of the ballistic portion of the launch. This makes vehicle system design approaches that provide for jettison of the hardware necessary to deploy a sail in space highly valuable. It also places a premium on vehicle system design engineering that takes into account the most mass efficient way to perform all required post-launch spacecraft functions, particularly those that involve propulsive events and attitude control and stabilization. Although sail technology may offer the possibility of propellantless propulsion and attitude control, many potential sailcraft mission scenarios may benefit from, or even require, jettison of the sail at some point in the mission, requiring the spacecraft to carry a conventional capability for attitude control and propulsive events after sail jettison. Adding the extra mass required to implement a propellantless method for attitude 
control, such as vanes or a gimbaled-mass-on-a-boom system, during the sail-attached portion of the mission saves propulsion subsystem mass for the overall vehicle use after sail jettison.

L'Garde and the team of JPL and Ball Aerospace used the concepts discussed above to improve the performance of their sailcraft from the ST-5 proposal through the 20 meter GSD program. A preliminary assessment of the benefits provided by implementing the above concepts and their enhancements to the Heliostorm mission are provided in Reference 14. Much of the mass savings came as a result of selecting a thinner material ( 2 micron Mylar). Additional mass savings were brought about by moving to a completely propellantless attitude control system using a set of tip vanes to provide roll, pitch and yaw control of the sailcraft. The vane design includes all component required for stowage in the canister, rotation of the vane into the plane of the sail for deployment, and finally to provide the cant angle to provide passive stability during operation. The boom were lightened by implementing a striped net design that allows the solar loads to be more efficiently spread along the length of the boom, with the sail laid loosely on the supporting stripped net with little stress. Sail wrinkles in the radial direction formed by a small amount of extra sail material are designed to absorb any lateral deformations in the film due to thermal effects. Lateral deformations are absorbed by the additional material, and the deformation from net element to net element is absorbed by slight changes in the billow between net elements. In this way, the net elements and not the sail material dictate the overall shape of the sail effectively decoupling the global sail shape from the membrane material properties. Since the booms are not sized to withstand the bending generated by the solar flux alone, a tensioned truss or spreader system is used to allow the boom to absorb the bending. The spreader system consists of lightweight composite spreader bars mounted to rigid rings integrated into the boom and Kevlar truss lines connecting the spreader bars together.

\section{A. Sail Design.}

Figure 5 shows top and side views of the deployed sailcraft as it would appear on orbit. Key features illustrated include the sail membrane, which dominates the plan view, and four beams, which deploy the membrane and support it against solar radiation pressure loads. The beams are tapered from a base diameter of $9.8 \mathrm{~cm}$ to the tip diameter of $3.5 \mathrm{~cm}$. The booms are 4.5 mils thick and manufactured with embedded resin coated Kevlar lines that rigidized when exposed to the cold of space. The design also includes four control vanes, which are articulated to provide 3-axis attitude control for the sailcraft and spacecraft elements in the center of the sail inside the circular aperture at the conjunction of the four sail support beams. The four solar array panels and the HGA and its boom are shown in their deployed configurations. The four solar array panels, which are sized to provide a positive power balance for all sail orientations without articulation. The High Gain Antenna (HGA) is spaced away from the S/C element and placed in the plane of the sail by an extendable boom. It is articulated in 2-axes to allow communication with the earth in any sail orientation. The $50 \mathrm{Kg}$ science payload has been sized assuming a $1 \mathrm{~g} / \mathrm{cc}$ density. It mounts between the $\mathrm{S} / \mathrm{C}$ element and the plane of the sail membrane to provide it with a direct view of the sun. No portion of the $\mathrm{S} / \mathrm{C}$ elements are more than $750 \mathrm{~mm}$ from the plane of the sail.

\section{B. Carrier Design}

Figure 5, bottom image, shows the carrier design that would be jettisoned following deployment of the sail propulsion system. The most critical design requirement is for the carrier to support the relatively low density stowed solar sail, plus the spacecraft elements and the science payload against the launch loads such as shock, sustained g-loads, and vibration. The carrier also provides electrical energy for sail deployment as the sailcraft arrays are stowed until after the sail is deployed. It does this using a combination of carrier solar arrays and a large battery. Because the solar sail's control vanes are stowed and ineffective until the sail is completely deployed, the carrier must provide attitude control between separation from the LV until the conclusion of sail deployment. The carrier uses a cold-gas RCS to provide control. The sailcraft star cameras aided by a carrier mounted a strap-down laser IRU determines the carrier attitude. Two low gain antennas provide close to spherical coverage for receipt of the command uplink and to support near-earth and contingency telemetry downlinks. Finally, to minimize the sailcraft separated mass, the carrier provides all the pressurant needed for deployment of the sail itself and its control vanes. The pressurant is stored in a carrier mounted tank, which also supplies the gas for the carrier RCS. Primary carrier elements include the thrust tube, which interfaces to the LV at its aft end, and the strut-braced sail support shelf which, with the four spreader bar supports, carries the stowed sail during launch and ascent. The four carrier array panels mount to the aft side of the sail support shelf 

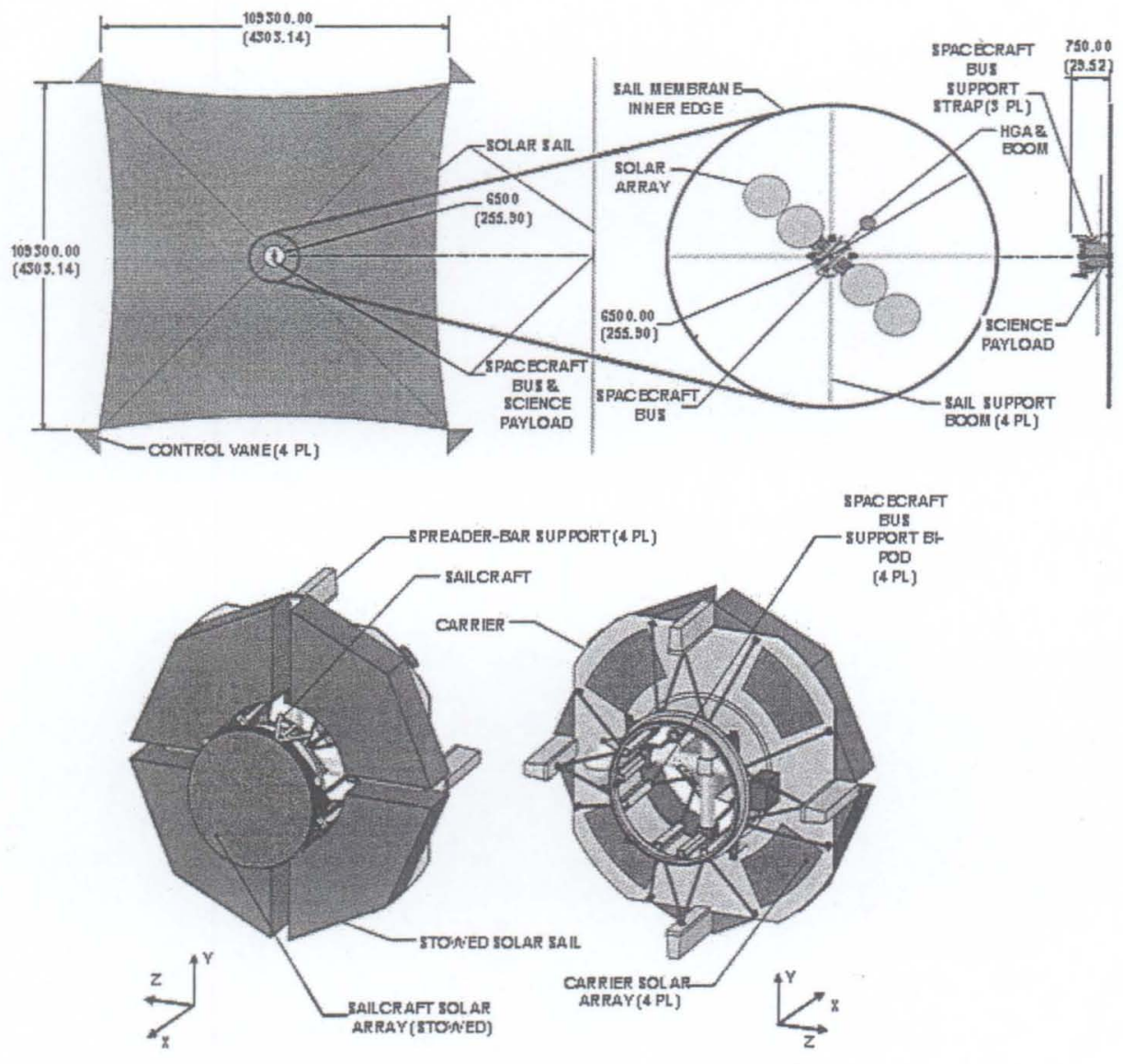

Nobs: Dimention in $\mathrm{m} m$ (in)

Figure 5: Updated Heliostorm Mission Concept

Two LGA's on opposite sides of the shelf provide for communications when the sailcraft antennas are stowed or covered by the carrier.

\section{Sail Deployment}

Once the sailcraft has successfully separated from the upper stage deployment can be initiated. Vane deployment is initiated by rotating the vane booms from their stowed position into proper position for deployment. The vane booms are deployed which pull the vane membranes into their deployed configuration. Next, the spreader system, which has been pulled together for stowage, is released in preparation for deployment. The main boom deployment is initiated by introducing inflation pressure into the stowed booms. The booms simultaneously deploy the sails and the spreader system drawing the Kevlar tension cables into position by deploying the rigid rings in a sequence. An inflation control system carefully monitors the deployment length of each boom and modulates the amount of inflation gas introduced to each boom to ensure the deployment progresses symmetrically. After the sail has been fully deployed, the tip vanes are canted back to provide passive attitude stability. Once equilibrium temperature is achieved and the structure is fully rigidized, the carrier is released. The sailcraft is now in its final configuration and providing thrust.

\section{Mission Design}

It is important to note that this mission concept, and the associated mass allocations, does not include the option for a halo orbit around the L1 point. This is a riskier approach compared to the ST-5 concept where a ballistic trajectory is flown to a halo orbit around L1 and then the sail is deployed to fly to the subL1 point. Under the GSD program, L'Garde has perfected an enhanced boom packing concept, allowing the diagonal dimension of a stowed 100 meter sail to decrease from $213 \mathrm{~cm}$ to $140 \mathrm{~cm}$. By reducing this

\section{American Institute of Aeronautics and Astronautics}


dimension and taking the risk of not having a operating spacecraft at L1 if the sail fails to deploy, the entire spacecraft can now be launched on a Taurus class vehicle, compared to a Delta II launched required for the ST-5 sailcraft, saving approximately $\$ 40$ million in launcher costs.

\section{Comparison of 1999 ST-5 and New-Technology Heliostorm Sailcraft Designs}

Table 3 summarizes the key aspects of the ST-5 Geostorm sailcraft and new-technology-based Heliostorm sailcraft designs, as just described. Table 4 breaks down the mass of the sail propulsion system. The column labeled "Post Goddard Boom test" reflects the modifications to the boom that were the result of boom only thermal vacuum testing at Goddard Space Flight Center in December of 2003. Table 5 details the mass breakout for the entire sailcraft and carrier for both designs. The key point here is that with the use of thinner sails and a clever design of the jettisonable carrier, the science payload that the sail can carry has increased from $5 \mathrm{~kg}$ to $50 \mathrm{~kg}$, which accounts for the majority of the difference between columns 3 and 4 of Table 3 . Figure 6 graphically shows the advancement in warning time based on the characteristic acceleration of the sailcraft. The $\mathrm{L} 1$ point is .993 astronomical units (AU) from the sun, so it is located at the right side of the graph. The ST- 5 design had a goal of maneuvering to $.983 \mathrm{AU}$, however

Table 3: ST-5 and Updated Heliostorm Mission Comparison

\begin{tabular}{|c|c|c|c|}
\hline \multicolumn{4}{|c|}{ Sailcraft Comparison } \\
\hline Item & $\begin{array}{l}1999 \text { NMP ST-5 } \\
\text { Proposal }\end{array}$ & $\begin{array}{c}\text { Start of GSD } \\
\text { Program }\end{array}$ & $\begin{array}{l}\text { End of GSD } \\
\text { Program }\end{array}$ \\
\hline \multicolumn{4}{|l|}{ System Characteristic Performance Metric } \\
\hline - Sailcraft Characteristic Acceleration & $0.182 \mathrm{~mm} / \mathrm{s} 2$ & $0.356 \mathrm{~mm} / \mathrm{s} 2$ & $0.522 \mathrm{~mm} / \mathrm{s} 2$ \\
\hline - Operational Station Location & $0.983 \mathrm{AU}$ & $0.974 \mathrm{AU}$ & $0.967 \mathrm{AU}$ \\
\hline - Sailcraft Areal Density (dry) & $42.6 \mathrm{~g} / \mathrm{m}^{2}$ & $9.48 \mathrm{~g} / \mathrm{m}^{2}$ & $14.82 \mathrm{~g} / \mathrm{m}^{2}$ \\
\hline - Sail Propulsion Subsystem Areal Density & $18.62 \mathrm{~g} / \mathrm{m}^{2}$ & $5.11 \mathrm{~g} / \mathrm{m}^{2}$ & $5.68 \mathrm{~g} / \mathrm{m}^{2}$ \\
\hline \multicolumn{4}{|l|}{ Sailcraft System } \\
\hline - Mass(dry) & $222.1 \mathrm{~kg}$ & $94.8 \mathrm{~kg}$ & $148.3 \mathrm{~kg}$ \\
\hline - Power (On-Station) & $193.3 \mathrm{~W}$ & No change & same \\
\hline - Attitude Stabilization & Spin & 3-axis using vanes & same \\
\hline - Attitude Control/Propulsion & \begin{tabular}{|l|} 
Conventional \\
monopropellant $\mathrm{Hz}$
\end{tabular} & $\begin{array}{l}\mathrm{Hz} \text { system used } \\
\text { during deployment }\end{array}$ & same \\
\hline \multicolumn{4}{|l|}{ Sail Propulsion Subsystem (SPS) } \\
\hline -Booms/Structure & $\begin{array}{|lr|}\text { Inflatable } & \text { UV- } \\
\text { rigidized } & \text { Kevlar. } \\
\text { Linear } & \text { mass } \\
\text { density: } & 41.1 \mathrm{~g} / \mathrm{m}^{2}\end{array}$ & \begin{tabular}{|lr} 
Inflatable & sub-Tg- \\
rigidized & Kevlar. \\
Linear & mass \\
density: & $30.5 \mathrm{~g} / \mathrm{m}^{2}$
\end{tabular} & $\begin{array}{|lr|}\text { Inflatable } & \text { sub-Tg- } \\
\text { rigidized } & \text { Kevlar. } \\
\text { Linear mass } & \text { density: } \\
31.5 \mathrm{~g} / \mathrm{m}^{2} & \end{array}$ \\
\hline - Membrane & $\begin{array}{l}\text { 8-micron-thick } \\
\text { Kapton }\end{array}$ & $\begin{array}{l}\text { 2-micron-thick } \\
\text { mylar }\end{array}$ & same \\
\hline -Vanes & Not used & Used & Used \\
\hline - Jettisonable Elements & $\begin{array}{|lr|}\begin{array}{l}\text { Inflation } \\
\text { sail }\end{array} & \text { system, } \\
\text { canister } & \text { stowage } \\
\end{array}$ & Carrier module & Carrier module \\
\hline Payload/Instrumentation & $4.5 \mathrm{~kg}$ total & No change & $\begin{array}{l}50 \quad \mathrm{~kg} \text { science } \\
\text { package }\end{array}$ \\
\hline
\end{tabular}

American Institute of Aeronautics and Astronautics 


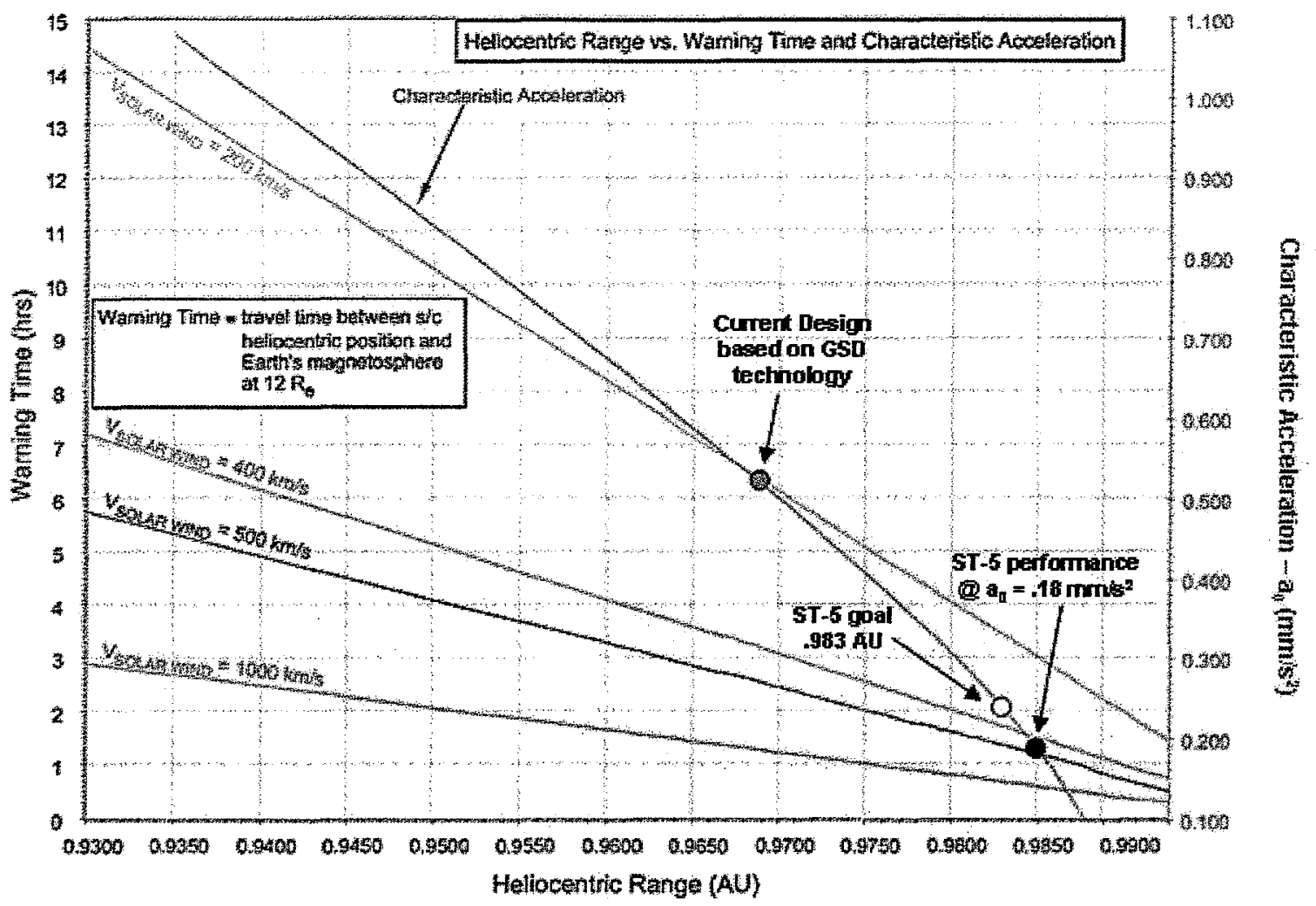

Figure 5: Heliocentric Distance vs. Warning Times

the best achievable was .986 AU. The Heliostorm design based new technologies demonstrated under the ISPT GSD program can achieve a position at $.969 \mathrm{AU}$ with a corresponding increase in the amount of warning time for CMEs.

\section{CONCLUSION}

Described herein is a concept for a new-technology-based Heliostorm Warning Mission sailcraft design. The sailcraft is capable of operating at a station location inside the Earth's L1 point near 0.969 AU. Positioned here, the sailcraft offers an improvement in solar storm warning time equivalent to a factor of nearly 2 compared to the 1999 ST-5 Geostorm proposal sailcraft, with that sailcraft positioned at 0.984 AU. The new sailcraft design makes maximal use of new developments in sail design sponsored by NASA's ISPT Program which make viable the scaling up of inflatable-based rigidizable sail designs.

\section{ACKNOWLEDGEMENT}

This work was funded in whole or in part by the In-Space Propulsion Technology Program, which is managed by NASA's Science Mission Directorate in Washington, D.C. The program objective is to develop in-space propulsion technologies that can enable or benefit near and mid-term NASA space science missions by significantly reducing cost, mass or travel times.

\section{REFERENCES}

1. NASA Science Mission Directorate (SMD) Draft Heliophysics Roadmap, April, 10, 2006, http://sec.gsfc.nasa.gov/HeliophysicsRoadmap4106.pdf

2. J. West, NOAA/NASA/DOD Geostorm Warning Mission, JPL Internal Document D-13986, 18 October 1996.

3. C. McInnis, Solar Sailing: Technology, Dynamics, and Mission Applications, 1999.

4. J. West, NMP ST-5 Solar Sail Project Concept Study Report, July 15, 1999.

5. J. West and B. Derbes, Solar Sail Vehicle System Design for the Geostorm Warning Mission, -AIAA-2000-5326, September 21, 2000. 
6. D. Murphy, "Validation of A Scalable Solar Sailcraft", 53rd JANNAF Propulsion Meeting, December 2005

7. J. Gaspar et al., "Testing Of A 20-Meter Solar Sail System", 53rd JANNAF Propulsion Meeting, December 2005

8. B. Taleghani et al, "20 Meter Solar Sail Analysis And Correlation", 53rd JANNAF Propulsion Meeting, December 2005

9. G. Laue, D. Case, J. Moore, "Fabrication and Deployment Testing of Solar Sail Quadrants for a 20-meter Solar Sail Ground Test System Demonstration", 41st AIAA Joint Propulsion Conference, July 2005, AIAA 2005-3930

10. D. Lichodziejewski et al., "Vacuum Deployment and Testing Of a 20 meter Solar Sail System", 47th AIAA/ASME/ASCE/AHS/ASC Structures, Structural Dynamics, and Materials Conference, May 2006, AIAA 20061705

11. D. Sleight et al., "Structural Analysis and Test Comparison of a 20-Meter Inflation-Deployed Solar Sail", 47th AIAA/ASME/ASCE/AHS/ASC Structures, Structural Dynamics, and Materials Conference, May 2006, AIAA 20061706

12. T. Mann et al., "Ground Testing A 20-Meter Inflation Deployed Solar Sail", 47th AIAA/ASME/ASCE/AHS/ASC Structures, Structural Dynamics, and Materials Conference, May 2006, AIAA 2006-1707

13. G. Singh, Attitude Control for the Geostorm Warning Mission, JPL IOM EM 3455-98-08, 12 October 1998.

14. J. West, The Geostorm Warning Mission: Enhanced Opportunities Based on New Technologies, AAS 04-102, February, 2004 
Table 4: Sail Propulsion System Mass Comparison

\begin{tabular}{|c|c|c|c|c|c|c|c|}
\hline \multirow{2}{*}{\multicolumn{8}{|c|}{$\begin{array}{l}\text { LGMS100A Main sc Projected Area (m2) } \\
\text { Closest Solar Approach (AU) }\end{array}$}} \\
\hline & & & & & & & \\
\hline & \multicolumn{3}{|c|}{ Phase 1 Concept Design } & Post Goddard & \multicolumn{3}{|c|}{ Phase 3 Final Design } \\
\hline Mainsall Quadrant Component & Estimated & Contingency & Mature & Boom Test & Estimated & Contingency & Mature \\
\hline $2 \mu$ Mylar quadrant (ST5 is $8 \mu$ Kapton) & 6,704 & $5 \%$ & 7,039 & N/A & 6,654 & \multirow{8}{*}{$\begin{array}{l}5 \% \\
20 \% \\
20 \% \\
30 \% \\
20 \% \\
20 \% \\
\end{array}$} & 5,997 \\
\hline $900 \mathrm{~A}$ frontside aluminum & 620 & $15 \%$ & 713 & N/A & 517 & & 740 \\
\hline 200 A backside chromium & 368 & $15 \%$ & 423 & N/A & 914 & & 1,097 \\
\hline quadrant features & 597 & $20 \%$ & 716 & N/A & 534 & & 694 \\
\hline stripe net & 70 & $15 \%$ & 81 & N/A & 103 & & 124 \\
\hline membrane management & 136 & $15 \%$ & 156 & N/A & 148 & & 178 \\
\hline mainsail quadrant system, each & 8,495 & \multirow[t]{2}{*}{$7 \%$} & 9,129 & \multirow[t]{2}{*}{ N/A } & 8,980 & & 9,830 \\
\hline 4 mainsail quadrants & 33,980 & & 36,515 & & 35,920 & & 39,319 \\
\hline boom system & 1,273 & $15 \%$ & 1,469 & 1,489 & & 1,926 \\
\hline unis & 528 & $15 \%$ & 607 & 523 & 641 & $30 \%$ & 833 \\
\hline spiral wrap & 177 & $15 \%$ & 204 & 203 & 216 & $30 \%$ & 281 \\
\hline bladder & 262 & $15 \%$ & 301 & 270 & 309 & $20 \%$ & 371 \\
\hline encapsulation & 96 & $10 \%$ & 106 & 157 & 117 & $20 \%$ & 140 \\
\hline insulation & 202 & $20 \%$ & 242 & 219 & 215 & $30 \%$ & 280 \\
\hline PBO rings & B & $10 \%$ & 9 & 16 & 18 & $20 \%$ & 22 \\
\hline spreader system total & 501 & $16 \%$ & 583 & 580 & \multicolumn{2}{|l|}{481} & 590 \\
\hline spreader bars with torsion web & 297 & $15 \%$ & 342 & 287 & 307 & $20 \%$ & 368 \\
\hline spreader wires & 92 & $10 \%$ & 101 & 162 & 43 & $20 \%$ & 52 \\
\hline bay rings & 112 & $25 \%$ & 140 & 131 & 131 & $30 \%$ & 170 \\
\hline beam deployment control system & 425 & $16 \%$ & 493 & 284 & \multicolumn{2}{|l|}{478} & 595 \\
\hline boom holdback straps & 34 & $15 \%$ & 39 & 27 & 48 & $30 \%$ & 62 \\
\hline ring \& boom fold doubler tapes & 12 & $15 \%$ & 14 & 10 & 30 & $20 \%$ & 36 \\
\hline tip mandrel with tip cap & 99 & $20 \%$ & 119 & 65 & 117 & $30 \%$ & 152 \\
\hline line management pockets & 4 & $15 \%$ & 5 & & 7 & $20 \%$ & 8 \\
\hline quarter of center box with base cap & 52 & $15 \%$ & 60 & 13 & 52 & $30 \%$ & 68 \\
\hline extensiometer line & 7 & $10 \%$ & 8 & & 7 & $20 \%$ & 8 \\
\hline HeaterNane motor control wires & 217 & $15 \%$ & 250 & 169 & 217 & $20 \%$ & 260 \\
\hline mainsail beam, each & 2,199 & \multirow[t]{2}{*}{$16 \%$} & 2,545 & \multirow[t]{4}{*}{2,353} & 2.475 & & 3.112 \\
\hline 4 mainsail beams & 8,796 & & 10,180 & & 9,900 & & 12,448 \\
\hline \multicolumn{7}{|l|}{ LGV3OA Vane Projected Area $\left(\mathrm{m}^{\wedge} 2\right)$} & \\
\hline \multicolumn{7}{|l|}{ Closest Solar Approach } & \\
\hline \multicolumn{8}{|l|}{ Vane Component } \\
\hline vane panel & 103 & $8 \%$ & 111 & N/A & 110 & $10 \%$ & 120 \\
\hline vane struts & 370 & $30 \%$ & 481 & N/A & 476 & $30 \%$ & 619 \\
\hline base deployment yokes \& actuator & 400 & $30 \%$ & 520 & N/A & 400 & $30 \%$ & 520 \\
\hline vane mass, each & 873 & \multirow[t]{3}{*}{$27 \%$} & 1.109 & & 986 & & 1,259 \\
\hline 4 vanes & 3,492 & & 4,435 & & 3,944 & & 5,037 \\
\hline Sail System & 46.268 & & 51.129 & & 49,764 & & 56,804 \\
\hline Sail Areal Monait & & & 511 & & & & 5 คค \\
\hline
\end{tabular}


Table 5: Sailcraft Mass Comparison

\begin{tabular}{|c|c|c|c|c|c|c|c|}
\hline \multirow{2}{*}{\multicolumn{8}{|c|}{$\begin{array}{l}\text { LGMS100A Main sc Projected Area }(\mathrm{m} 2) \\
\text { Closest Solar Approach (AU) }\end{array}$}} \\
\hline & & & & & & & \\
\hline & \multicolumn{3}{|c|}{ Phase 1 Concept Design } & Post Goddard & \multicolumn{3}{|c|}{ Phase 3 Final Design } \\
\hline Malnsall Quadrant Component & Estimated & Contingency & Mature & Boom Test & Estimated & Contingency & Mature \\
\hline $2 \mu$ Mylar quadrant (ST5 is $8 \mu$ Kapton) & 6.704 & $5 \%$ & 7.039 & N/A & 6,664 & $5 \%$ & 6.997 \\
\hline 900 A frontside aluminum & 620 & $15 \%$ & 713 & N/A & 617 & $20 \%$ & 740 \\
\hline 200 A backside chromium & 368 & $15 \%$ & 423 & N/A & 914 & $20 \%$ & 1,097 \\
\hline quadrant features & 597 & $20 \%$ & 716 & N/A & 534 & $30 \%$ & 694 \\
\hline stripe net & 70 & $15 \%$ & 81 & N/A & 103 & $20 \%$ & 124 \\
\hline membrane management & 136 & $15 \%$ & 156 & N/A & 148 & $20 \%$ & 178 \\
\hline mainsail quadrant system, each & 8,495 & $7 \%$ & 9,129 & N/A & 8,980 & & 9,830 \\
\hline 4 mainsail quadrants & 33,980 & & 36,515 & & 35.920 & & 39,319 \\
\hline boom system & 1,273 & $15 \%$ & 1.469 & 1.489 & 1.516 & & 1,926 \\
\hline unis & 528 & $15 \%$ & 607 & 523 & 641 & $30 \%$ & 833 \\
\hline spiral wrap & 177 & $15 \%$ & 204 & 203 & 216 & $30 \%$ & 281 \\
\hline bladder & .262 & $15 \%$ & 301 & 270 & 309 & $20 \%$ & 371 \\
\hline encapsulation & 96 & $10 \%$ & 106 & 157 & 117 & $20 \%$ & 140 \\
\hline insulation & 202 & $20 \%$ & 242 & 219 & 215 & $30 \%$ & 280 \\
\hline PBO rings & 8 & $10 \%$ & 9 & 16 & 18 & $20 \%$ & 22 \\
\hline spreader system total & 501 & $16 \%$ & 583 & 580 & 481 & & 590 \\
\hline spreader bars with torsion web & 297 & $15 \%$ & 342 & 287 & 307 & $20 \%$ & 368 \\
\hline spreader wires & 92 & $10 \%$ & 101 & 162 & 43 & $20 \%$ & 52 \\
\hline bay rings & 112 & $25 \%$ & 140 & 131 & 131 & $30 \%$ & 170 \\
\hline beam deployment control system & 425 & $16 \%$ & 493 & 284 & 478 & & 595 \\
\hline boom holdback straps & 34 & $15 \%$ & 39 & 27 & 48 & $30 \%$ & 62 \\
\hline ring \& boom fold doubler tapes & 12 & $15 \%$ & 14 & 10 & 30 & $20 \%$ & 36 \\
\hline tip mandrel with tip cap & 99 & $20 \%$ & 119 & 65 & 117 & $30 \%$ & 152 \\
\hline line management pockets & 4 & $15 \%$ & 5 & & 7 & $20 \%$ & e \\
\hline quarter of center box with base cap & 52 & $15 \%$ & 60 & 13 & 52 & $30 \%$ & 68 \\
\hline extensiometer line & 7 & $10 \%$ & 8 & & 7 & $20 \%$ & B \\
\hline Heater/vane motor control wires & 217 & $15 \%$ & 250 & 169 & 217 & $20 \%$ & 260 \\
\hline mainsail beam, each & 2,199 & $16 \%$ & 2,545 & 2,353 & 2.475 & & 3,112 \\
\hline 4 mainsail beams & 8,796 & & 10,180 & & 9,900 & & 12,448 \\
\hline LGV30A Vane Projected Area $\left(m^{\wedge} 2\right)$ & & & & & & & \\
\hline Closest Solar Approach & & & & & & & \\
\hline Vane Component & & & & & & & \\
\hline vane panel & 103 & $8 \%$ & 111 & N/A & 110 & $10 \%$ & 120 \\
\hline vane struts & 370 & $30 \%$ & 481 & N/A & 476 & $30 \%$ & 619 \\
\hline base deployment yokes \& actuator & 400 & $30 \%$ & 520 & N/A & 400 & $30 \%$ & 520 \\
\hline vane mass, each & 873 & $27 \%$ & 1,109 & & 986 & & 1.259 \\
\hline 4 vanes & 3,492 & & 4,435 & & 3,944 & & 5,037 \\
\hline & 45768 & & 51120 & & & & \\
\hline $\begin{array}{l}\text { Sail System } \\
\text { Sail Areal Density }\end{array}$ & 46.268 & & $\frac{51.129}{5.11}$ & & 49.764 & & $\frac{56.804}{5.68}$ \\
\hline
\end{tabular}

